\title{
The anti-angiogenic role of soluble-form VEGF receptor in malignant gliomas
}

\author{
SHINGO TAKANO, EIICHI ISHIKAWA, MASAHIDE MATSUDA, NORIAKI SAKAMOTO, \\ HIROYOSHI AKUTSU, TETSUYA YAMAMOTO and AKIRA MATSUMURA
}

\author{
Department of Neurosurgery, Faculty of Medicine, University of Tsukuba, Tsukuba, Ibaraki 305-8575, Japan
}

Received September 19, 2016; Accepted November 21, 2016

DOI: 10.3892/ijo.2016.3810

\begin{abstract}
Anti-angiogenic therapy represents a promising, new therapeutic modality for malignant gliomas. The present study was designed to define the malignant glioma cases most suitable for anti-angiogenic therapy and to demonstrate the efficacy of anti-angiogenic therapy using soluble-form Flt1 (sFlt1) gene delivery in mice. In human malignant glioma samples (39 glioblastomas, 21 anaplastic astrocytomas and 4 anaplastic oligoastrocytomas), protein expression of VEGF, and its specific natural inhibitor, sFlt1, as well as vessel architecture were assessed. Among these variables, VEGF $>1000 \mathrm{ng} / \mathrm{ml}$, $\mathrm{VEGF} / \mathrm{sFlt1}$ ratio $>1$, vessel density $>30$, and vessel area $>7 \%$ were prognostic factors for malignant gliomas. VEGF/sFlt1 ratio $>1$ was the most powerful prognostic marker for survival in multivariate analysis. The sFlt1 gene was also successfully introduced into U87 glioma cells in vitro, resulting in 31\% tumor growth inhibition in vivo. sFlt1-transfected tumor demonstrated high sFlt-1 expression along with diminished vessel density and area compared with the control tumor. In transfected tumor, VEGF expression was decreased in the viable area, but still high in the hypoxic area. sFlt1 and VEGF expression was re-evaluated in vitro using glioma cells under normoxic and hypoxic conditions. For sFlt1-transfected cells, VEGF expression was upregulated, but sFlt1 expression was downregulated, resulting in an increase of VEGF/sFlt1 ratio in hypoxic conditions. We conclude that malignant gliomas with a high $\mathrm{VEGF} / \mathrm{sFlt1}$ ratio and large vessel area are good candidates for anti-angiogenic therapy. Soluble Flt1 gene delivery was demonstrated to inhibit glioma growth, but this was limited in hypoxic areas.
\end{abstract}

\section{Introduction}

Angiogenesis is crucial to the growth of malignant glioma. Anti-angiogenic therapy thus represents a promising modality

Correspondence to: Dr Shingo Takano, Department of Neurosurgery, Faculty of Medicine, University of Tsukuba, 1-1-1 Tennoudai, Tsukuba, Ibaraki 305-8575, Japan

E-mail: shingo4@md.tsukuba.ac.jp

Key words: angiogenesis, glioma, hypoxia, soluble-form Flt1, survival, vascular endothelial growth factor for treating this condition. Recently, reports were published on large clinical trials for newly diagnosed glioblastoma treated with standard chemoradiation therapy plus vascular endothelial growth factor (VEGF) antibody, bevacizumab $(1,2)$. These reports demonstrated a significant improvement of progression-free survival (PFS) with/without better quality of life. However, there was no benefit for overall survival in either trial. One reason for this is considered to be VEGF resistance. As such, there is a need for further improvements in antiangiogenic treatment of glioma, for example, by identifying useful biomarkers for VEGF antibody treatment, which was not achieved in these two large clinical trials (3). Biomarkers for bevacizumab have been reported in breast and prostate cancer. Serum VEGF concentration was identified as a predictive biomarker for breast cancer (4), but not for prostate cancer (5). However, a preliminary report on a bevacizumab biomarker project described that serum VEGF concentration, as well as various angiogenic factors, including VEGFR-1, VEGFR-2, E-selectin, VEGFR-3, IL-8, bFGF, PDGF-C, VEGF-C, PIGF and ICAM-1, cannot be used as biomarkers, and tissue vascular density and area are also not predictive factors for bevacizumab $(3,6)$. Further anti-angiogenic clinical trials (on cilengitide, cediranib and enzastaurin) also failed to reveal a survival benefit for glioblastoma (7). To achieve a survival benefit for gliomas with anti-angiogenic therapy, we need to establish a strong and useful biomarker for antiangiogenic therapy of gliomas and a new strategy combining chemotherapy and/or immunotherapy with an anti-angiogenic agent.

Current defined endogenous angiogenic stimulators and inhibitors in neoplasms have been well described. In particular, it has been shown that the balance between stimulators and inhibitors regulates tumor angiogenesis, resulting in tumor growth $(8,9)$. Many endogenous angiogenesis inhibitors have been discovered, and the list continues to grow $(10,11)$. Endogenous protein inhibitors have the advantages of low toxicity, high tolerance, low risk of drug resistance, and a higher likelihood of specifically blocking pathological neovascularization without affecting the normal vasculature (12). Some of them have reached the clinical trial stage or are already on the market; these include endostatin (endostar) and angiostatin (13-15). Other inhibitors have served as parent molecules from which derivative analogues have been developed and reached the clinical trial stage, such as thrombospondin-1 
and its analogue ABT-510 (16,17). Nevertheless, to date, the clinical efficacy of these inhibitors in humans is still questionable. Only endostar, a modified recombinant endostatin, has been approved as an anticancer drug in China (18).

Soluble Flt-1 (sFlt1) is a soluble form of VEGF receptor 1 (VEGFR-1), which is measurable in conditioned medium and cell/tissue lysate and inhibits angiogenesis. The function of sFlt1 is assumed to be mainly inhibitory, complexing VEGF and thus acting as a regulator of VEGF-A bioavailability. Flt1 has more than 10-fold higher affinity to VEGF-A, even in soluble form, but has approximately a 10 -fold lower thyrosine kinase activity than VEGFR-2. In addition, sFlt1 can form heterodimers with transmembrane VEGFR-2, preventing autophosphorylation, and thus, abolishing signaling in a dominant-negative fashion (19). sFlt1, an endogenous angiogenesis inhibitor, is a candidate for anti-angiogenic therapy for malignant gliomas. Among several different approaches for transferring anti-angiogenic genes (sFlt1, angiostatin and endostatin), sFlt1 gene transfer was found to be the most potent for inhibiting tumor growth in a preclinical animal model (20).

In the present study, sFlt1 and VEGF were measured in a series of human glioma tissues using specific enzymelinked immunosorbent assay (ELISA) in order to determine whether their concentrations, and especially the net balance of VEGF/sFlt1, predict patient survival and angiogenic potential. The effectiveness of sFlt1 gene delivery as an endogenous angiogenic inhibitor against glioma growth and angiogenesis was also investigated in a mouse model.

\section{Materials and methods}

Tissue preparation. Tissues from 69 cases of human malignant glioma (Table I) (glioblastoma 39, anaplastic astrocytoma 21 and anaplastic oligoastrocytoma 4) were obtained during surgery at the University of Tsukuba Hospital between 1997 and 2004. The tissues were immediately stored at $-80^{\circ} \mathrm{C}$ until use. The tissues were thawed, $50-\mathrm{mg}$ samples were homogenized in 10-fold extraction buffer $(25 \mathrm{mM}$ Tris- $\mathrm{HCl}$, $\mathrm{pH} 7.4,100 \mathrm{mM} \mathrm{NaCl}, 20 \mathrm{mM} \mathrm{NH}_{4} \mathrm{HCO}_{3}$ ) and then they were again stored at $-80^{\circ} \mathrm{C}$ until use. The protein concentration was measured by DC protein assays (Bio-Rad Laboratories, Hercules, CA, USA). The rest of the tissue was fixed in formalin and embedded in paraffin.

sFlt1 and VEGF ELISA. The concentrations of sFlt1 and VEGF were measured in tumor extract supernatants using Quantikine ${ }^{\mathrm{TM}}$ Human sFlt1 and VEGFimmunoassays(DVR100 and DVE00, respectively; R\&D Systems, Minneapolis, MN, USA). sFlt1 and VEGF levels were normalized to total extract protein concentrations, and are expressed as pg sFlt1 and $\mathrm{VEGF} / \mathrm{mg}$ total extract protein.

Immunohistochemistry and angiogenic profile. The Dako LSAB2 kit for mouse and rabbit primary antibody (Dako, Glostrup, Denmark) was used (21). Tissue sections were deparaffinized and incubated with $10 \%$ normal goat serum in phosphate-buffered serum (PBS) for $20 \mathrm{~min}$. The sections were then incubated with a polyclonal anti-VEGF antibody, A-20 (Santa Cruz Biotechnology, Inc., Santa Cruz, CA, USA), at a concentration of $10 \mu \mathrm{g} / \mathrm{ml}$, a monoclonal MIB-1 antibody
Table I. Prognostic factors in malignant gliomas (Hazard model).

\begin{tabular}{|c|c|c|c|}
\hline & Hazard ratio & $95 \% \mathrm{CI}$ & P-value \\
\hline $\begin{array}{l}\text { Univariate } \\
\text { VEGF (pg/mg) }\end{array}$ & & & \\
\hline$>1000$ vs. $<1000$ & 2.17 & $1.28-3.70$ & $<0.01$ \\
\hline $\begin{array}{c}\text { sVEGFR } 1(\mathrm{pg} / \mathrm{mg}) \\
<1000 \text { vs. }>1000\end{array}$ & 0.95 & $0.56-1.61$ & ns \\
\hline $\begin{array}{l}\text { VEGF/R1 ratio } \\
>1 \text { vs. }<1\end{array}$ & 2.79 & $1.61-4.86$ & $<0.001$ \\
\hline $\begin{array}{l}\text { Pathology } \\
\text { Grade IV vs. III }\end{array}$ & 2.65 & $1.53-4.58$ & $<0.001$ \\
\hline $\begin{array}{l}\text { MIB1 }(\%) \\
>20 \text { vs. }<20\end{array}$ & 1.77 & $1.05-3.00$ & $<0.05$ \\
\hline $\begin{array}{l}\text { p53 }(\%) \\
>10 \text { vs. }<10 \%\end{array}$ & 0.85 & $0.48-1.50$ & $\mathrm{~ns}$ \\
\hline $\begin{array}{l}\text { Density } \\
>30 \text { vs. }<30\end{array}$ & 1.18 & $0.70-1.97$ & ns \\
\hline $\begin{array}{l}\text { Vessel area }(\%) \\
>7 \text { vs. }<7\end{array}$ & 2.39 & $1.35-4.21$ & $<0.01$ \\
\hline Multivariate & & & \\
\hline $\begin{array}{l}\text { VEGF/R1 ratio } \\
>1 \text { vs. }<1\end{array}$ & 1.99 & $1.08-3.66$ & $<0.05$ \\
\hline $\begin{array}{l}\text { Pathology } \\
\text { Grade IV vs. III }\end{array}$ & 1.81 & $0.98-3.33$ & ns \\
\hline $\begin{array}{l}\text { MIB1 }(\%) \\
>20 \text { vs. }<20\end{array}$ & 1.47 & $0.86-2.49$ & ns \\
\hline
\end{tabular}

(Immunotech Laboratories, Inc., Monrovia, CA, USA) in phosphate-buffered saline (PBS) overnight at $4^{\circ} \mathrm{C}$, a monoclonal p53 antibody (clone DO7; Dako) in PBS overnight at $4^{\circ} \mathrm{C}$, and a monoclonal CD34 antibody (BD Biosciences, San Jose, CA, USA) at a dilution of $1 / 50(10 \mu \mathrm{g} / \mathrm{ml})$ in PBS for $60 \mathrm{~min}$ at room temperature. Chromatographically purified mouse IgG and rabbit IgG (Dako) at the same IgG concentration were used as negative controls. Sections were incubated with biotin-conjugated goat anti-mouse or anti-rabbit immunoglobulin for $10 \mathrm{~min}$, followed by washing in PBS for $10 \mathrm{~min}$. The sections were then incubated with peroxidaseconjugated streptavidin solution for $5 \mathrm{~min}$, followed by washing in PBS for $5 \mathrm{~min}$. Sections were then stained with freshly prepared aminoethylcarbazole solution for $10 \mathrm{~min}$, followed by washing for $5 \mathrm{~min}$ in tap water. Next, sections were counterstained with hematoxylin and mounted with aqueous mounting media. The intracellular VEGF immunostaining was assessed using a semi-quantitative scale (-, not detected; + , moderate; and ++ , strong). The rates of nuclei positive for MIB-1 and p53 were determined by counting at least 1000 tumor cells. 
The number of vessels, area occupied with vessels, and mean vessel diameter at a x200 magnified field $\left(1.0 \mathrm{~mm}^{2}\right)$ were morphometrically measured in microvessel 'hot spots' (i.e., microscopic areas containing the densest collections of microvessels, as initially identified under low-power magnification) using an Olympus microscope, AHBT3 (Olympus, Tokyo, Japan) and WinROOF software (Mitani Corp., Tokyo, Japan) on CD34-stained tissue sections. Vascular density and area were determined by averaging the number of vessels and area in the three most vascularized areas.

Cell culture and sFlt1 transfection. The human glioma cell line U-87 MG was obtained from the American Type Culture Collection (ATCC; Rockville, MD, USA). Cells were maintained in minimum essential medium (MEM) supplemented with $10 \%$ fetal calf serum (FCS) in a humidified atmosphere containing $5 \% \mathrm{CO}_{2}$ at $37^{\circ} \mathrm{C}$.

In order to investigate the effect of sFlt1 gene overexpression in vitro and in vivo, a human sFlt1 gene (2223 bp)-encoding plasmid, pBLAST45-hsFLT1 (\#pbla-hsflt1; Invivogen, Inc., San Diego, CA, USA), was transfected into U87 malignant glioma cells using Fugene6 (Invivogen). Transfectants were selected using blasticidine. Among the three clones obtained, two were confirmed to express sFlt1 by reverse transcription polymerase chain reaction (RT-PCR). mRNA expression of sFlt1 was not observed in U87 cells, which were the parental cells, or in empty vector transfectant (empty), which did not contain the sFlt1 gene. One of the clones expressing sFlt1 (Fig. 3A, lane 1) was used in the subsequent experiments.

The cells were incubated with $5 \% \mathrm{CO}_{2}$ at $37^{\circ} \mathrm{C}$ for $24 \mathrm{~h}$ under hypoxic $\left(0.1 \% \mathrm{O}_{2}\right)$ or normoxic conditions $\left(20 \% \mathrm{O}_{2}\right)$. Hypoxic conditions were established by placing the cells in a molecular incubator chamber (Model, APM-30D; Astec, Columbus, $\mathrm{OH}, \mathrm{USA}$ ) with a gas mixture consisting of $1 \% \mathrm{O}_{2}, 5 \% \mathrm{CO}_{2}$ and balanced $\mathrm{N}_{2}$ for the indicated period. Conditioned medium was collected for western blot analysis and ELISA.

Cell proliferation assay (MTT assay). Cell proliferation assays were performed using the CellTiter $96^{\mathrm{TM}}$ Aqueous nonradioactive proliferation assay (Promega Corp., Madison, WI, USA), as previously described (22). This assay measures the reduction of a tetrazolium compound,3-(4,5-dimethylthiazol2-yl)-5-(3-carboxymethoxyphenyl)-2-(4-sulfophenyl)-2H-tetrazolium (MTT), by living cells to a formazan product. Briefly, 5000 glioma cells, at $1 \times 10^{5} / \mathrm{ml}$ in MEM with $10 \%$ FCS, were plated in 96-well plates (Becton-Dickinson, Lincoln Park, NJ, USA). The cells were incubated for 6,18 or $36 \mathrm{~h}$. At the end of the incubation period, the microplate wells were supplemented with $20 \mu \mathrm{l}$ of a freshly prepared solution containing a mixture of a tetrazolium compound and an electron coupling reagent (phenazine methosulfate) and incubated for $2 \mathrm{~h}$ at $37^{\circ} \mathrm{C}$. Then, the optical density at $490 \mathrm{~nm}$ was read on an automatic microplate reader (Model 550; Bio-Rad Laboratories). The experiment was repeated at least three times in triplicate wells.

Western blot analysis. The tissues and the cell pellets were homogenized with an ultrasonic homogenizer on ice in $1 \mathrm{ml}$ of extraction buffer [ $25 \mathrm{mM}$ Tris, $100 \mathrm{mM} \mathrm{NaCl}, 20 \mathrm{mM}$ $\mathrm{NH}_{4} \mathrm{HCO}_{3}$, pH 7.5, protease inhibitor cocktail; Complete Mini
(Roche), one tablet] per $100 \mathrm{mg}$ wet weight of tissue and the protein lysates were obtained after centrifugation at $50,000 \mathrm{x} \mathrm{g}$ for $30 \mathrm{~min}$ at $4^{\circ} \mathrm{C}$. Lysates containing $50 \mu \mathrm{g}$ of total protein, as estimated by the Bradford method using bovine serum albumin (BSA) as a standard, were separated on 12\% sodium dodecyl sulfate polyacrylamide gel, electroblotted onto a $0.2-\mu \mathrm{m}$ nitrocellulose membrane (Bio-Rad Laboratories), and immunoassayed with rabbit polyclonal anti-VEGF antibody (A-20, $100 \mu \mathrm{g} / \mathrm{ml}$; Santa Cruz Biotechnology) at a dilution of 1:200 and mouse monoclonal anti-human sFlt1 antibody (ab9540; Abcam) at a dilution of 1:100. The immunocomplexes formed were visualized with alkaline phosphatase-conjugated anti-rabbit or anti-mouse immunoglobulin G (IgG) using the ECL Western blotting analysis system (Amersham Pharmacia Biotech, Piscataway, NJ, USA).

U87 severe combined immunodeficiency (SCID) mouse subcutaneous model. After the implantation of $1 \times 10^{5}$ U87 cells (sFlt1 transfectant: sFlt1, empty transfectant:empty) in the flank of a 6-week-old male SCID mouse (Clea, Inc., Tokyo Japan), U87 transfectant tumor tissue fragments were removed and then reimplanted into the flank of another SCID mouse. Harvested tumor fragments $1 \mathrm{~mm}^{3}$ in size were implanted into the flank of 6 SCID mice for each transfectant. The size of the subcutaneous tumor was measured using calipers. Eighteen days after the implantation, the tumor tissue was removed. Some of the tissue was immediately fixed in $10 \%$ phosphate-buffered formalin for $48 \mathrm{~h}$, embedded in paraffin, and used for routine pathological diagnosis and immunohistochemistry. The rest of the tissue was immediately homogenized for protein extraction, frozen with liquid nitrogen for mRNA extraction, and stored at $-70^{\circ} \mathrm{C}$. Ethics approval was from the University of Tsukuba, Tsukuba, Japan.

In order to evaluate the hypoxic area in tumor sections, pimonidazole hydrochloride (Hypoxyprobe-1; Chemicon International, Temecula, CA, USA) was administered at $120 \mathrm{mg} / \mathrm{kg}$ just before sacrifice. Paraffinized tissue sections were stained with anti-pimonidazole antibody (Chemicon International) at a dilution of 1:20 in PBS for $60 \mathrm{~min}$ at room temperature to visualize the hypoxic area (22).

RNA isolation and RT-PCR. Total RNA was extracted from the transfectants and from frozen tumor tissue derived from them (5 empty transfectants and 6 sFlt1 transfectants) using RNeasy Mini kit (Qiagen GmbH, Hilden, Germany). Quantitative RT-PCR for sFlt1 and VEGF mRNA in glioma cells and glioma tissues was performed. We performed RT-PCR with the GeneAmp ${ }^{\mathrm{TM}}$ RNA PCR kit (Perkin-Elmer Cetus, Norwalk, CT, USA). Briefly, $1 \mu \mathrm{g}$ of total RNA was reverse-transcribed by MuLV reverse transcriptase in the presence of random hexamer, followed by the indicated cycles of PCR reaction $\left(95^{\circ} \mathrm{C}\right.$ for $1 \mathrm{~min}, 55^{\circ} \mathrm{C}$ for $1 \mathrm{~min}$ and $72^{\circ} \mathrm{C}$ for $1 \mathrm{~min}$ ) in the presence of $2 \mu \mathrm{M}$ sFlt1-specific primers (32 cycles), VEGF-specific primers (28 cycles) or $\beta$-actin-specific primers (16 cycles) as a control. The sFlt1 primers were designed so that the reverse primer (5'-TATGTTTCTTCCC ACAGTCCCAAC-3') corresponds to positions 2178-2201, and the forward primer (5'-CTAATTGTCAATGTGAAACC CCAG-3') corresponds to positions 1821-1844. The VEGF primers included a reverse primer (5'-CCTGGTGAGAG ATCTGGTTC-3') spanning bases 861-842 and a forward 

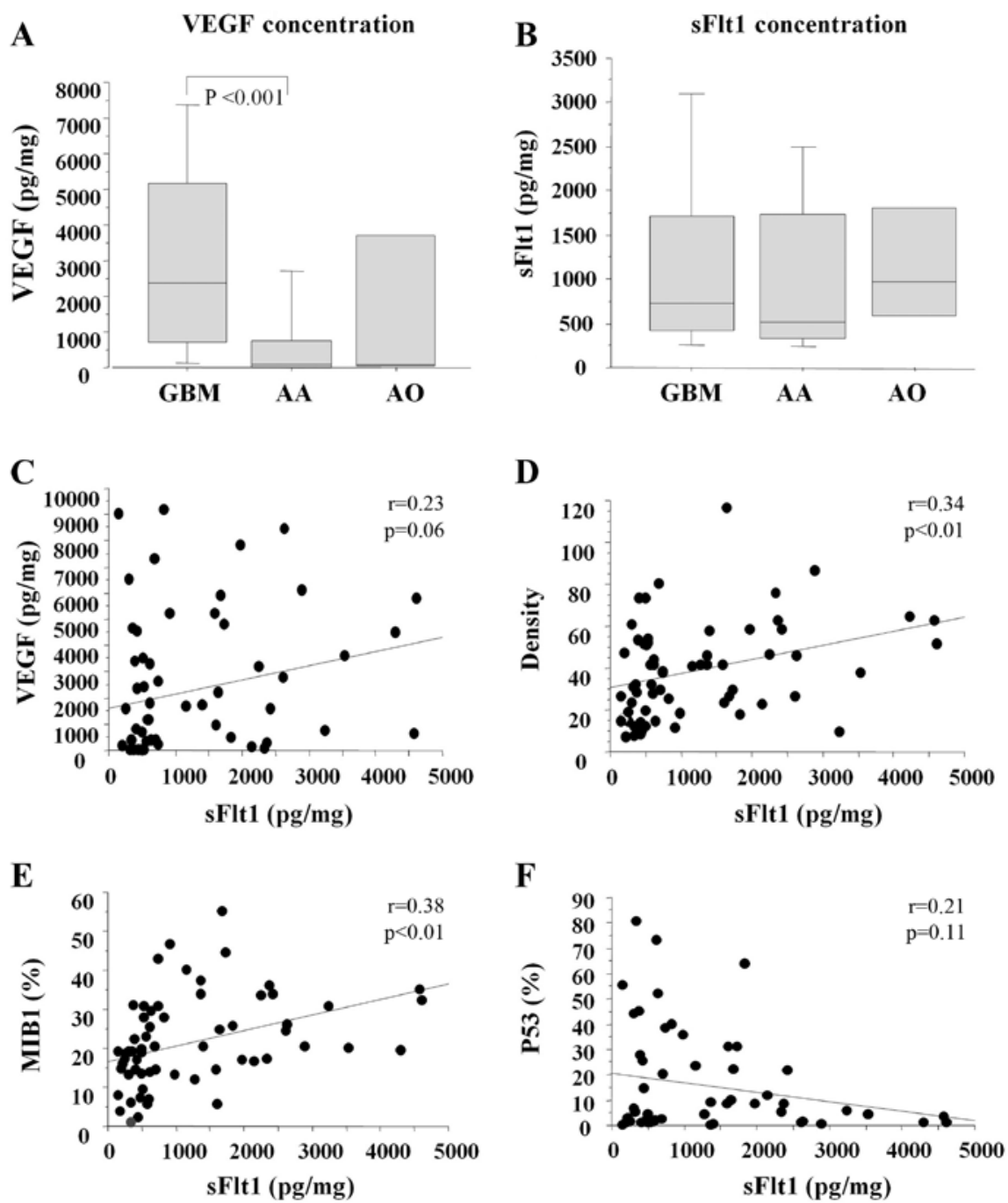

Figure 1. Angiogenic profiles of patients with malignant glioma. (A) VEGF concentration. VEGF concentration of GBM is significantly higher than that of AA. (B) sFlt1 concentration. (C) Correlation between sFlt1 and VEGF concentration. (D) Correlation between sFlt1 concentration and vascular density. (E) Correlation between sFlt1 concentration and MIB1 positivity. (F) Correlation between sFlt1 concentration and p53 positivity. GBM, glioblastoma; AA, anaplastic astrocytoma; AO, anaplastic oligodendroglioma.

primer (5'-TCGGGCCTCCGAAACCATGA-3') spanning bases 141-160. The $\beta$-actin primers included a reverse primer (5'-GGAGTTGAAGGTAGTTTCGTG-3') spanning bases 2429-2409 and a forward primer (5'-CGGGAAATCGTGC GTGACAT-3') spanning bases 2107-2126. The predicted sizes of the amplified sFlt1 and $\beta$-actin DNA products were 380 and $214 \mathrm{bp}$, respectively. The VEGF primers were chosen because they amplified exons 3-8 and allowed the different VEGF splicing variants to be distinguished. PCR products of 516 and 648 bp corresponded to VEGF121 and VEGF165, respectively. Quantification of the levels of these RT-PCR products was performed on a Macintosh computer using the public domain NIH Image program (developed at the U.S. National Institutes of Health, Bethesda, MD, USA).

Statistical analyses. Vascular density, vessel area, vessel diameter, vessel perimeter, vessel roundness, MIB-1 positivity, tumor volume, VEGF concentration and sFlt-1 concentration are expressed as mean \pm standard deviation. Statistically significant differences between the groups were determined using a one-way analysis of variance and the Tukey's test. All
P-values are two-sided; values are considered statistically significant at $\mathrm{P}<0.05$. The survival time was calculated by the Kaplan-Meier method. Differences in survival were assessed by the log-rank test. For categorical variables, two-tailed Fisher's exact test was used.

\section{Results}

Angiogenic profiles and angioarchitectural features as prognostic factors in malignant gliomas. Our treatment strategy for malignant gliomas in the study period was total or subtotal removal, following by $40-\mathrm{Gy}$ whole-brain and 20-Gy local boost irradiation combined with PAV (procarbazine, ACNU and vincristine) chemotherapy (23) and interferon- $\beta$ administration. Upon recurrence, PE (cisplatin and etoposide) and temozolomide chemotherapy and/or immunotherapy, including locolesional natural killer or cytotoxic $\mathrm{T}$ lymphocyte injection (24) were carried out. The median survival time of all cases of malignant glioma was 19.2 months (grade IV, glioblastoma: 11.2 months, grade III, anaplastic astrocytoma/ anaplastic oligodendroglioma: 30.9 months). 
A

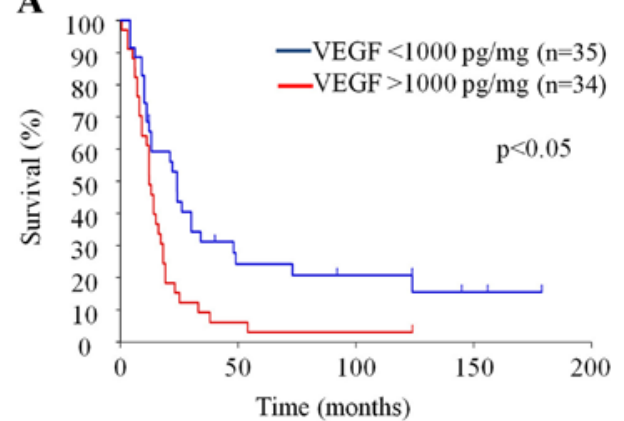

B

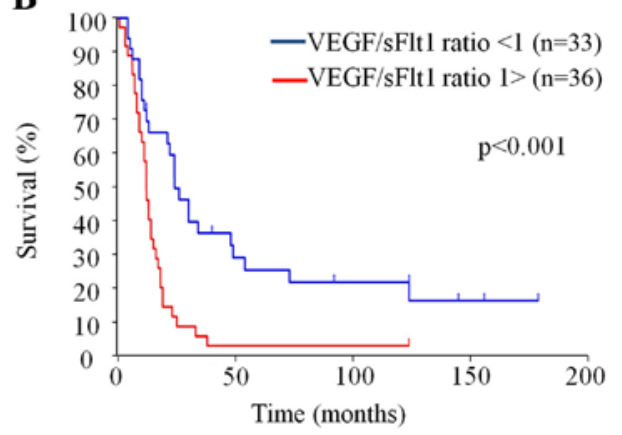

C

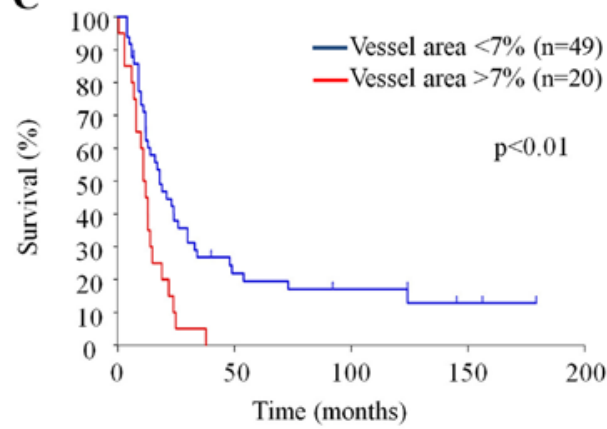

Figure 2. Survival curves with VEGF concentration (A), VEGF/sFlt1 ratio (B) and vessel area (C). (A) Overall survival is significantly longer with VEGF $<1000 \mathrm{pg} / \mathrm{mg}(51.3 \mathrm{mo})$ than VEGF $>1000 \mathrm{pg} / \mathrm{mg}$ (18.0 mo) [Stratified hazard ratio, 2.17 (95\% CI, 1.28-3.70), $\mathrm{P}<0.05$ by log-rank test]. (B) Overall survival is significantly longer with VEGF/sVEGFR ratio $<1$ (54.9 mo) than VEGF/sVEGFR ratio >1 (16.4 mo) [Stratified hazard ratio, $2.79(95 \%$ CI, 1.61-4.86), $\mathrm{P}<0.001$ by log-rank test]. (C) Overall survival is significantly longer with vessel area $<7 \%$ (44.8 mo) than vessel area $>7 \%(13.1 \%)$ [Stratified hazard ratio, 2.39 (95\% CI, 1.35-4.21), $\mathrm{P}<0.01$ by log-rank test]. Please note statistically significant difference is stronger with VEGF/sFlt1 ratio compared with VEGF concentration alone.

Fig. 1 and Table I show the angiogenic profiles of each case. VEGF concentration was significantly high in glioblastoma compared with that in anaplastic astrocytoma, while sFlt1 concentration was not. sFlt1 concentration was significantly correlated with vessel density $(\mathrm{r}=0.34, \mathrm{P}<0.01)$ and MIB1 positivity $(\mathrm{r}=0.38, \mathrm{P}<0.01)$, and weakly correlated with VEGF concentration $(\mathrm{P}=0.06)$. VEGF/sFlt1 ratio $(>1)$, pathology (grade IV), MIB1\% (>20\%) and vessel area $(>7 \%)$ were poor prognostic factors as determined by univariate analysis. Among these, VEGF/sFlt1 ratio $>1$ was the strongest independent prognostic factor by multivariate analysis (hazard ratio 1.99, 95\% confidence interval 1.08-3.66; $\mathrm{P}<0.05$ ).

Survival time was evaluated by the Kaplan-Meier analysis (Table II and Fig. 2). This analysis again demonstrated the survival benefit associated with VEGF concentration
Table II. Prognostic factors in malignant gliomas (KaplanMeier).

\begin{tabular}{|c|c|c|c|}
\hline Parameters & $\mathrm{n}$ & MST (month) & Log-rank \\
\hline \multicolumn{4}{|c|}{ VEGF (pg/mg) } \\
\hline$>1000$ & 34 & 18.0 & $<0.05$ \\
\hline$<1000$ & 35 & 51.3 & \\
\hline \multicolumn{4}{|c|}{ sVEGFR1 (pg/mg) } \\
\hline$<1000$ & 40 & 32.1 & ns \\
\hline$>1000$ & 29 & 36.0 & \\
\hline \multicolumn{4}{|c|}{ VEGF/R1 ratio } \\
\hline$>1$ & 36 & 16.4 & $<0.001$ \\
\hline$<1$ & 33 & 54.9 & \\
\hline \multicolumn{4}{|l|}{ Pathology } \\
\hline Grade IV & 40 & 19.5 & $<0.001$ \\
\hline Grade III & 29 & 53.7 & \\
\hline \multicolumn{4}{|l|}{ MIB1 (\%) } \\
\hline$>20$ & 34 & 20.2 & $<0.05$ \\
\hline$<20$ & 35 & 48.2 & \\
\hline \multicolumn{4}{|l|}{ p53 (\%) } \\
\hline$>10$ & 24 & 26.2 & ns \\
\hline$<10$ & 37 & 39.9 & \\
\hline \multicolumn{4}{|c|}{ Density $/ 0.1 \mathrm{~mm}^{2}$} \\
\hline$>30$ & 38 & 31.8 & ns \\
\hline$<30$ & 31 & 36.2 & \\
\hline \multicolumn{4}{|c|}{ Vessel area $(\%)$} \\
\hline$>7$ & 20 & 13.1 & $<0.01$ \\
\hline$<7$ & 49 & 44.8 & \\
\hline
\end{tabular}

ns, not significant.

( $<1000 \mathrm{pg} / \mathrm{mg}$ ), pathology (grade III), MIB-1\% (<20\%) and vessel area $(<7 \%)$. Although there was no survival benefit associated with sFlt1 concentration itself, VEGF/sFlt1 concentration ratio $\leq 1$ was the variable with the strongest survival benefit for cases of malignant glioma. The median survival time was 11.3 months for those with a ratio $>1$ and 28.7 months for those with a ratio $<1(\mathrm{P}<0.001)$. These results suggest that the balance of stimulators and inhibitors of angiogenesis is particularly important for the angiogenic evaluation of malignant gliomas. Each parameter was then evaluated only for glioblastomas. VEGF, VEGF/sFlt1 ratio, MIB1 and vessel density were not prognostic factors for this condition, but vessel area $>7 \%$ was a strong prognostic factor for the glioblastoma group alone (data not shown).

The effect of sFlt1 overexpression on glioma angiogenesis and growth. Under a microscope, both sFlt1 transfectant and empty vector transfectant showed a fusiform shape similar to that of the parental U87 cells. The growth rates of these transfectants and the parents were similar, as determined by the WST 8 assay (Fig. 3B-D).

In a subcutaneous model, glioma growth was significantly inhibited for the sFlt1 transfectant compared with that for the 
A
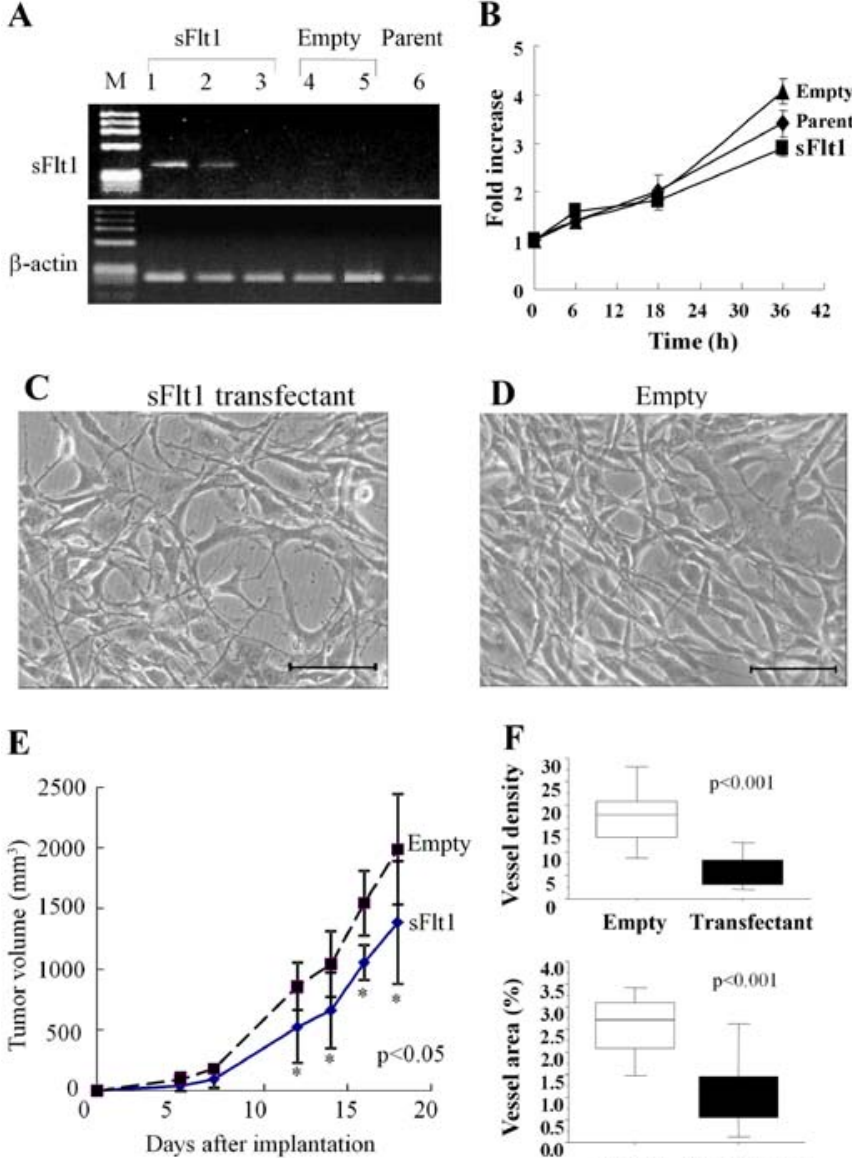
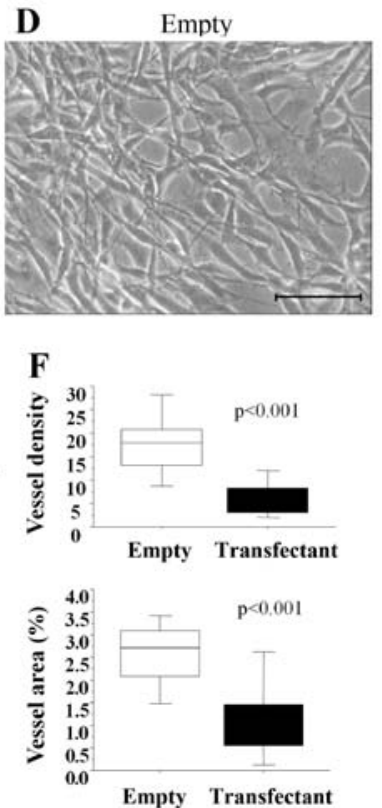

Figure 3. sFlt1 transfectant behavior in vitro (A-D) and in vivo (E and F). (A) sFlt1 expression of sFlt1 transfectant, empty vector transfectant and parental U87 cells. (B) Proliferation of each cell type. (C) Morphology of sFlt1 transfectant. (D) Morphology of empty vector transfectant. (E) Transfectant (sFlt1 and empty vector) glioma cell growth in subcutaneous model. Tumor volume is significantly smaller with sFlt1 transfectant compared to empty vector transfectant at day $12,14,16$ and 18 days ( $\mathrm{P}<0.05)$ (F) Vessel density and vessel area of transfectant (sFlt1 and empty vector) tumor tissues. Vessel density and vessel area are significantly lower with sFlt1 transfectant compared to empty vector transefectant.

empty vector transfectant (Fig. 3E; P<0.05). Tumor volume reduction for the sFlt1 transfectant was only $31 \%$. In tissue sections, vessel density and area were significantly decreased for the sFlt1 transfectant (Figs. $3 \mathrm{~F}$ and $4 \mathrm{~A}$ and $\mathrm{D} ; \mathrm{P}<0.001$ ). VEGF expression was also inhibited in the viable tumor area for the sFlt1 transfectant (Fig. 4B and E). However, even for the sFlt1 transfectant, there was still a pimonidazole-stained hypoxic area that was very similar to that in the empty transfectant, in which positive VEGF staining was observed (Fig. 4B, $\mathrm{C}, \mathrm{E}$ and $\mathrm{F}$ ). RT-PCR analysis of tumor tissues demonstrated that sFlt1 mRNA expression was significantly upregulated for the sFlt1 transfectant (Fig. 5A and B). Western blot analysis of tumor tissues also demonstrated that sFlt1 protein expression was significantly upregulated (Fig. 5C). By contrast, VEGF mRNA and protein expression levels were not changed by sFlt1 transfection (Fig. 5A-C).

In order to investigate the mechanism by which the hypoxic area was maintained in tissue sections, the transfectant profile under hypoxic conditions was evaluated in vitro. First, RT-PCR analysis showed the upregulation of both VEGF $_{121}$
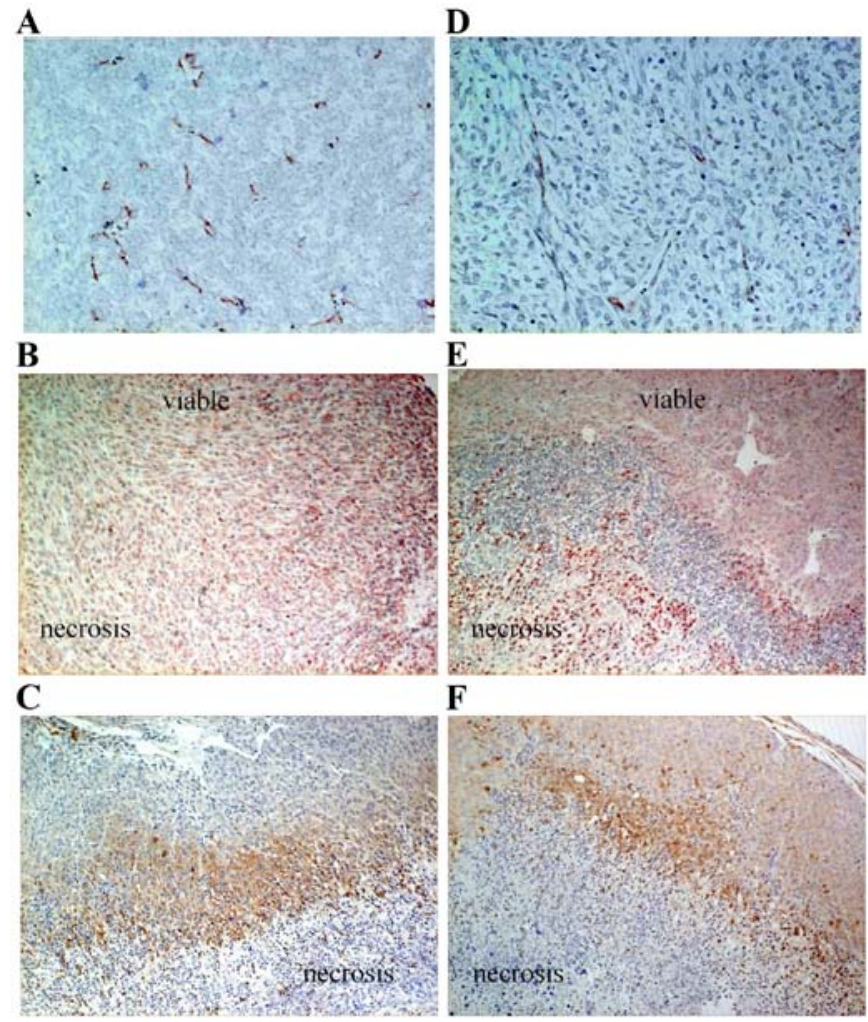

F

Figure 4. Histopathological examination of empty vector transfectant (A-C) and sFlt1 transfectant (D-F). (A and D) CD34 staining. (B and E) VEGF staining. Note the strong VEGF expression in the viable area of empty vector transfectant and downregulation of VEGF expression in the viable area, but not adjacent to the necrotic area, of sFlt1 transfectant tissue. (C and F) Pimonidazole staining. Note that the hypoxic area stained with pimonidazole is still present in sFlt1 transfectant tissue.

and $\mathrm{VEGF}_{165}$ expression, but not sFlt1 expression, under hypoxic conditions $\left(1 \% \mathrm{O}_{2}, 24 \mathrm{~h}\right)$ compared with that under normoxic ones $\left(20 \% \mathrm{O}_{2}, 24 \mathrm{~h}\right.$ ) (Fig. 6A and B). Second, the levels of VEGF and sFlt1 secretion into conditioned medium for the sFlt1 transfectant, empty transfectant, and parent were measured by western blotting under normoxic and hypoxic conditions $\left(1 \% \mathrm{O}_{2}, 24 \mathrm{~h}\right)$. As expected, VEGF secretion was upregulated for the three types of cells under hypoxic conditions. The sFlt1 transfectant secreted sFlt1 into the conditioned medium under normoxic conditions, but secreted little or none under hypoxia (Fig. 6C). sFlt1 concentration in the conditioned medium was precisely measured by sFlt1 ELISA and was detected only for the sFlt1 transfectant. The sFlt1 concentration was $8340.3 \pm 890.4 \mathrm{pg} / \mathrm{ml}$ under normoxic conditions and $1735.3 \pm 140.1 \mathrm{pg} / \mathrm{ml}$ under hypoxia, which were significantly different (Fig. 6D; $\mathrm{P}<0.01$ ).

\section{Discussion}

In the present study, we searched for prognostic factors for the survival of patients with malignant gliomas by measuring VEGF and sFlt1 concentrations, proliferation rate and vascular architecture. VEGF concentration, VEGF/sFlt1 concentration ratio, pathological grade of tumor, and vessel area were all identified as prognostic factors. Among these variables, VEGF/sFlt1 ratio was the strongest independent prognostic factor. The anti-angiogenic role of sFlt1 was then evaluated 
A

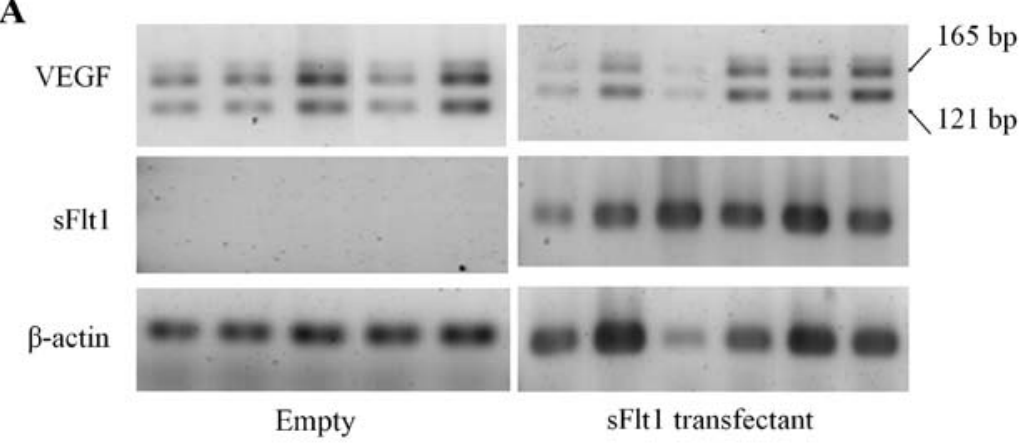

B
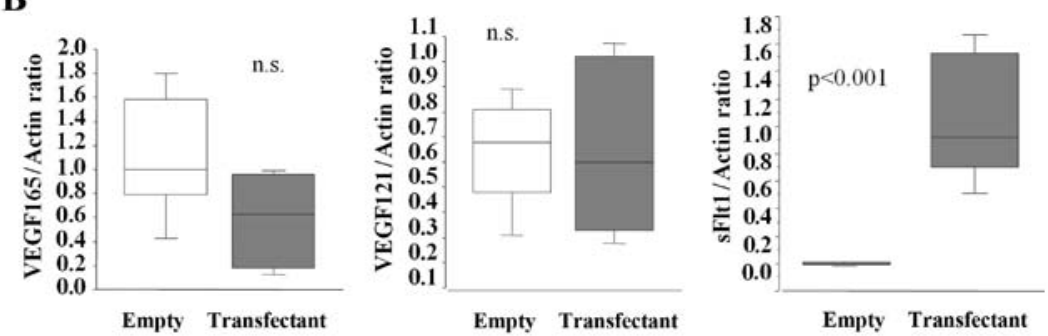

C

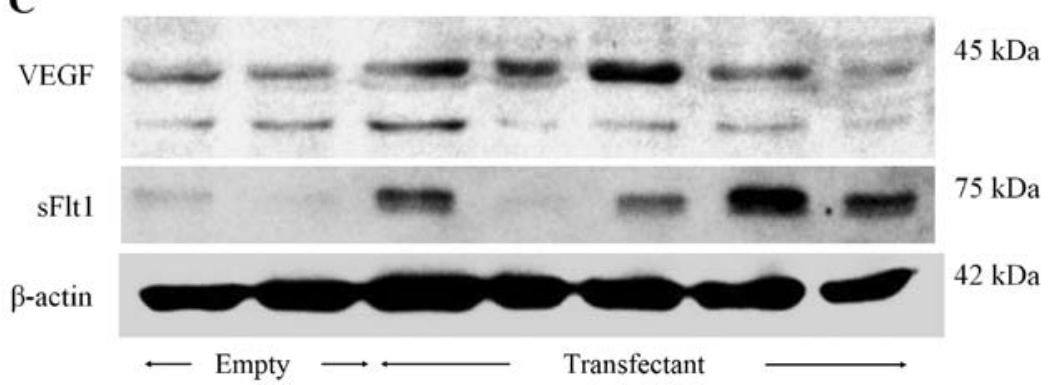

Figure 5. Molecular analysis of tumor tissue for empty vector and sFlt1 vector transfectants. (A) RT-PCR analysis of VEGF and sFlt1 expression. (B) Densitometric analysis of A for VEGF and sFlt1 expression. (C) Western blot analysis of VEGF and sFlt1 expression.

in vitro and in vivo by introducing the sFlt1 gene into glioma cells. This resulted in the inhibition of glioma growth and angiogenesis, but such effects were only moderate because angiogenic inhibition was not achieved under hypoxic conditions.

sFlt1 as a biomarker of glioma angiogenesis. For the potential biomarker sFlt1, two different variables can be measured, namely, its levels in tissue and circulation. It is important to verify this candidate for anti-angiogenic treatment in malignant gliomas by considering both of these alternatives. Concerning the tissue biomarker, the present study clearly showed that, among the variables in angiogenic profiles, vessel area and the ratio of VEGF to its endogenous inhibitor sFlt-1 strongly predict the prognosis of patients with malignant gliomas. Although the concentration of VEGF, but not that of sFlt1, was also a prognostic factor, the VEGF/sFlt1 concentration ratio should be considered a stronger independent prognostic factor. These results are useful for the further development of individualized anti-angiogenic therapy because gliomas with a high VEGF/sFlt1 ratio should be responsive to anti-angiogenic treatment.

Lamszus et al (25) reported that the concentrations of sFlt1 protein were markedly increased in glioblastomas compared with those in low-grade gliomas and normal brain. The concentration of sFlt1 correlated with the malignancy grade and was 12-fold higher in glioblastomas than in diffuse astrocytomas, with intermediate levels being exhibited in anaplastic astrocytomas. Although the absolute levels of sVEGFR-1 were increased in more malignant gliomas, the sVEGFR-1:VEGF-A ratio was decreased 2.6-fold in glioblastomas compared with that in diffuse astrocytomas, suggesting that the ensuing increased bioavailability of VEGF-A promotes angiogenesis. sFlt1 could be useful as an angiogenesis inhibitor in the specific context of human gliomas. In this study, the concentration of sFlt1 did not differ between glioblastoma and grade III glioma (anaplastic astrocytoma and anaplastic oligodendroglioma). The net balance between VEGF and sFlt1 would still be tilted towards angiogenesis in malignant gliomas. In the previous study mentioned above, no survival data related to the net balance of VEGF/sFlt1 were presented. However, we demonstrated a survival benefit associated with a lower VEGF/sFlt1 ratio in malignant gliomas.

Several studies have focused on tissue biomarkers associated with bevacizumab treatment. It has been observed in tissue studies conducted in patients with recurrent high-grade glioma treated with bevacizumab and irinotecan that high expression of VEGF was associated with a higher likelihood of achieving a radiographic response, but not increased survival (26). It was also observed in this same study that elevated levels of 

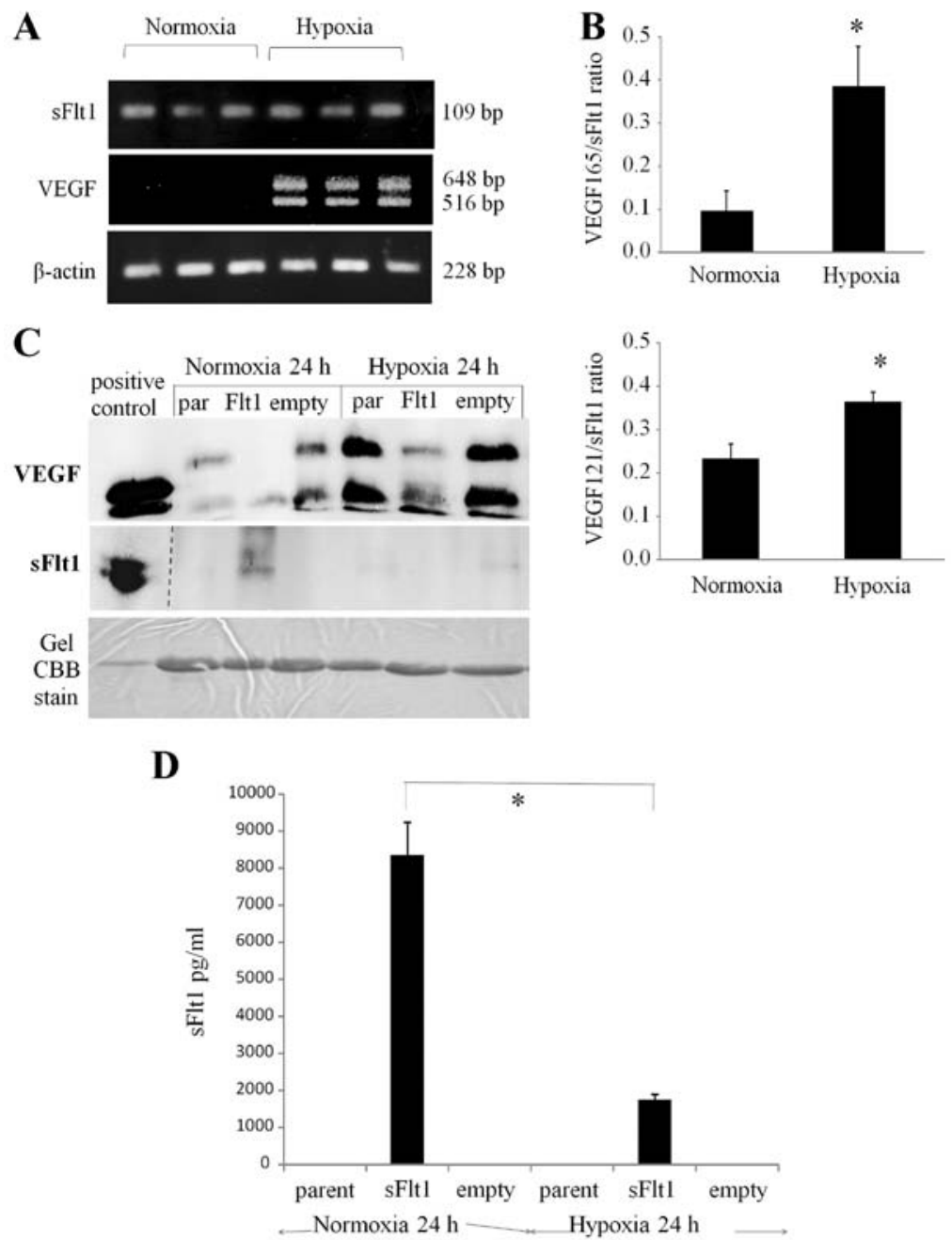

Figure 6. sFlt1 and VEGF expression of transfectant under normoxic and hypoxic conditions. (A) RT-PCR analysis. (B) Densitometric evaluation of VEGF/sFlt1 ratio. (C) Western blot analysis. Dotted line between lane 1 and lane 2 in sFlt1 picture indicates that lane 1 is derived from another picture. (D) ELISA quantitation. ${ }^{*} \mathrm{P}<0.01$

carbonic anhydrase 9, a hypoxic marker, were significantly associated with poor one-year survival. In contrast, in a study of patients with glioblastoma treated with bevacizumab and irinotecan with or without cetuximab (an EGFR inhibitor), no biomarker was predictive of response to treatment or prolongation of PFS (27). Finally, a retrospective autopsy study of patients with recurrent glioblastoma treated with various antiVEGF agents including bevacizumab showed that elevated numbers of $\mathrm{CD} 68^{+}$and $\mathrm{CD} 11^{+}$tumor-associated macrophages were associated with poor survival, indicating a potential biomarker of escape (28). In summary, several studies have identified different tumor tissue markers that may serve as biomarkers for response to treatment. However, the ratio of $\mathrm{VEGF} / \mathrm{sFlt1}$ concentrations, which we identified as an independent prognostic factor in malignant gliomas, has not yet been investigated in terms of response to anti-VEGF agents.

The incorporation of bevacizumab and other anti-VEGF agents into the early treatment of cancer patients would be significantly enhanced by the discovery of circulating biomarkers that can be used to establish rational guidelines for the selection and use of these agents. In rectal cancer, baseline serum sFlt-1 was found to be a predictive biomarker for therapies that include bevacizumab (29). However, reports of circulating biomarkers for glioma are limited. The AVAglio study, which included the evaluation of pretreatment plasma VEGF and sVEGFR-2, found no association with PFS (6). A similar lack of associations between pretreatment biomarkers, including VEGF and sVEGFR-2, and treatment outcome in patients with GBM was reported for cediranib, vatalanib and vandetanib (30-33). However, increases in serum sVEGFR-1 (sFlt1) have been found to be associated with poor survival in patients treated with cediranib (31). Duda et al (29) also reported that serum sFlt1 increased during anti-VEGF therapy in rectal cancer cases; they proposed that an increase of sFlt1 is a potential biomarker of resistance to anti-VEGF therapy. Unfortunately, the significance of circulating biomarkers in gliomas has still not been clarified.

sFlt1 as a target of anti-angiogenic molecules in malignant gliomas. We demonstrated that a higher sFlt1 concentration was strongly associated with higher vascular density in malignant glioma tissues. The levels of sFlt1 present in human glioma tissues were clearly insufficient to prevent neovascularization in malignant gliomas. A molar concentration of sFlt1 that exceeds that of VEGF by 2- to 200 -fold was reported to be required to obtain significant effects on 
endothelial chemotaxis in vitro (25). Therefore, considerably higher levels appear to be required to effectively inhibit the angiogenic effects of VEGF on a glioma xenograft model in vivo. We planned to perform sFlt1 gene transfer for glioma cells that have no sFlt1 expression in vitro.

In several animal models, adenovirus-mediated overexpression of sFlt1 in tumor cells was shown to inhibit the growth of melanoma and lung cancer in vivo $(34,35)$ and a mammalian cell-mediated approach effectively delivered sFlt-1 gene therapy and inhibited the angiogenesis and growth of thyroid cancer in vivo (36). However, some reports suggest that intravenous delivery of the sFlt-1 gene via adenoviral vectors results in the overexpression of sFlt-1 in the liver, leading to unacceptable hepatotoxicity (37). Therefore, tumor-specific targeting of vectors and tumor-specific expression strategies should be used to ensure clinically useful anti-angiogenic gene therapy. Previously, Goldman et al (38) reported that the growth of tumor cells transfected with sFlt1-expressing plasmid was inhibited in fibrosarcoma cells in a subcutaneous tumor model and prolonged the survival time of glioma cells in a transcranial model. In our in vitro study, sFlt1 was successfully expressed in glioma cells at the gene and protein levels and we confirmed its secretion into conditioned medium by transfectants in vitro. However, our in vivo study demonstrated that the growth inhibitory effect of sFlt1-transfected glioma cells was only $31 \%$, even with significant upregulation of sFt1 gene and protein expression in tumor tissues. We found that the target molecule VEGF was still present in the hypoxic area of tumor tissue in vivo. We also confirmed the downregulation of sFlt1 secretion of sFlt1 transfectants under hypoxic conditions in vitro. VEGF expression in the sFlt1 transfectants was upregulated similarly to that in the parental cells, resulting in the net balance of VEGF/sFlt1 being increased under hypoxic conditions. This increase was considered to limit the growth inhibitory effect in brain tumors in vivo. Downregulation of sFlt1 overexpression in lentiviral-constructed human endothelial cells under hypoxic conditions has been reported to occur by a mechanism involving mRNA alternative processing (39). In this study, under hypoxic conditions, mRNA expression was maintained, but protein secretion was inhibited.

Most solid tumors develop regions of low oxygen tension because of an imbalance between oxygen supply and consumption $(40,41)$. Several ideas have been proposed to overcome the downregulation of $\mathrm{VEGF} / \mathrm{sF}$ lt-1 ratio under hypoxic conditions. For example, strategies to treat tumors have been developed in which tumor cells are targeted with drugs or gene therapy vectors specifically activated under hypoxic conditions (42). Hypoxia in the tumor microenvironment provides ideal conditions for anaerobic microbes to survive. For example, Bifidobacterium infantis is a type of bifidobacteria that is non-pathogenic and anaerobic; thus, it can be transfected with an anti-angiogenic gene and selectively localize and proliferate in the hypoxic environment in several types of solid tumor after systemic application $(43,44)$. A hypoxiaresponsive glial cell-specific gene therapy vector for targeting pathological neovascularization has also been utilized (45). A wide variety of nanomedicine has been designed for cancer therapy, of which hypoxia-responsive copolymer for siRNA delivery is one example (46). New strategies for the delivery of anti-angiogenic agents, such as sFlt1, into hypoxic areas are required to ensure the long-term maintenance of an antiangiogenic effect.

In conclusion, a VEGF/sFlt1 ratio of $>1$ was identified as a predictor of poor survival in cases of malignant glioma, suggesting that the sFlt1 activity as an endogenous angiogenesis inhibitor regulates glioma angiogenesis. sFlt1 is thus, a candidate molecular target for glioma angiosuppression. However, future work should focus on the regulation of sFlt1 overexpression under hypoxic conditions.

\section{Acknowledgements}

We are grateful to Yoshiko Tsukada and Makiko Miyakawa for their excellent technical assistance. The present study was supported in part by a Grant-in-Aid for Scientific Research from the Ministry of Education, Culture, Sports, Science, and Technology of Japan (no. 15H04947 to S.T.), the Japan Brain Foundation (to S.T.) and the Japanese Foundation for Multidisciplinary Treatment of Cancer (to S.T.).

\section{References}

1. Chinot OL, Wick W, Mason W, Henriksson R, Saran F, Nishikawa R, Carpentier AF, Hoang-Xuan K, Kavan P, Cernea D, et al: Bevacizumab plus radiotherapy-temozolomide for newly diagnosed glioblastoma. N Engl J Med 370: 709-722, 2014.

2. Gilbert MR, Dignam JJ, Armstrong TS, Wefel JS, Blumenthal DT, Vogelbaum MA, Colman H, Chakravarti A, Pugh S, Won M, et al: A randomized trial of bevacizumab for newly diagnosed glioblastoma. N Engl J Med 370: 699-708, 2014.

3. Lu-Emerson C, Duda DG, Emblem KE, Taylor JW, Gerstner ER, Loeffler JS, Batchelor TT and Jain RK: Lessons from antivascular endothelial growth factor and anti-vascular endothelial growth factor receptor trials in patients with glioblastoma. J Clin Oncol 33: 1197-1213, 2015.

4. Shivakumar S, Prabhakar BT, Jayashree K, Rajan MG and Salimath BP: Evaluation of serum vascular endothelial growth factor (VEGF) and microvessel density (MVD) as prognostic indicators in carcinoma breast. J Cancer Res Clin Oncol 135: 627-636, 2009.

5. Botelho F, Pina F and Lunet N: VEGF and prostatic cancer: A systematic review. Eur J Cancer Prev 19: 385-392, 2010.

6. Nishikawa R, Saran F, Mason W, Wick W, Cloughesy TF, Henriksson R, Hilton M, Garcia J, Vogt T, Pallaud C, et al: Biomarker (BM) evaluations in the phase III AVAglio study of bevacizumab (Bv) plus standard radiotherapy (RT) and temozolomide (T) for newly diagnosed glioblastoma (GBM). J Clin Oncol 31: 2023, 2013.

7. Batchelor TT, Reardon DA, de Groot JF, Wick W and Weller M: Antiangiogenic therapy for glioblastoma: Current status and future prospects. Clin Cancer Res 20: 5612-5619, 2014.

8. Hanahan D and Folkman J: Patterns and emerging mechanisms of the angiogenic switch during tumorigenesis. Cell 86: 353-364, 1996.

9. Jain RK: Normalization of tumor vasculature: An emerging concept in antiangiogenic therapy. Science 307: 58-62, 2005.

10. Prea SM, Chan EC, Dusting GJ, Vingrys AJ, Bui BV and Liu GS: Gene therapy with endogenous inhibitors of angiogenesis for neovascular age-related macular degeneration: Beyond anti-VEGF therapy. J Ophthalmol 2015: 201726, 2015.

11. Rao N, Lee YF and Ge R: Novel endogenous angiogenesis inhibitors and their therapeutic potential. Acta Pharmacol Sin 36: 1177-1190, 2015.

12. Volpert OV, Zaichuk T, Zhou W, Reiher F, Ferguson TA, Stuart PM, Amin M and Bouck NP: Inducer-stimulated Fas targets activated endothelium for destruction by anti-angiogenic thrombospondin-1 and pigment epithelium-derived factor. Nat Med 8: 349-357, 2002.

13. Beerepoot LV, Witteveen EO, Groenewegen G, Fogler WE, Sim BK, Sidor C, Zonnenberg BA, Schramel F, Gebbink MF and Voest EE: Recombinant human angiostatin by twice-daily subcutaneous injection in advanced cancer: A pharmacokinetic and long-term safety study. Clin Cancer Res 9: 4025-4033, 2003. 
14. Kurup A, Lin C, Murry DJ, Dobrolecki L, Estes D, Yiannoutsos CT, Mariano L, Sidor C, Hickey R and Hanna N: Recombinant human angiostatin (rhAngiostatin) in combination with paclitaxel and carboplatin in patients with advanced nonsmall-cell lung cancer: A phase II study from Indiana University. Ann Oncol 17: 97-103, 2006.

15. Rong B, Yang S, Li W, Zhang W and Ming Z: Systematic review and meta-analysis of Endostar (rh-endostatin) combined with chemotherapy versus chemotherapy alone for treating advanced non-small cell lung cancer. World J Surg Oncol 10: 170, 2012.

16. Uronis HE, Cushman SM, Bendell JC, Blobe GC, Morse MA, Nixon AB, Dellinger A, Starr MD, Li H, Meadows K, et al: A phase I study of ABT-510 plus bevacizumab in advanced solid tumors. Cancer Med 2: 316-324, 2013.

17. Westphal JR: Technology evaluation: ABT-510, Abbott. Curr Opin Mol Ther 6: 451-457, 2004.

18. Cui C, Mao L, Chi Z, Si L, Sheng X, Kong Y, Li S, Lian B, Gu K, Tao M, et al: A phase II, randomized, double-blind, placebo-controlled multicenter trial of Endostar in patients with metastatic melanoma. Mol Ther 21: 1456-1463, 2013.

19. Davis-Smyth T, Chen H, Park J, Presta LG and Ferrara N: The second immunoglobulin-like domain of the VEGF tyrosine kinase receptor Flt-1 determines ligand binding and may initiate a signal transduction cascade. EMBO J 15: 4919-4927, 1996.

20. Kuo CJ, Farnebo F, Yu EY, Christofferson R, Swearingen RA, Carter R, von Recum HA, Yuan J, Kamihara J, Flynn E, et al: Comparative evaluation of the antitumor activity of antiangiogenic proteins delivered by gene transfer. Proc Natl Acad Sci USA 98: 4605-4610, 2001.

21. Takano S, Yoshii Y, Kondo S, Suzuki H, Maruno T, Shirai S and Nose T: Concentration of vascular endothelial growth factor in the serum and tumor tissue of brain tumor patients. Cancer Res 56: 2185-2190, 1996.

22. Takano S, Kamiyama H, Mashiko R, Osuka S, Ishikawa E and Matsumura A: Metronomic treatment of malignant glioma xenografts with irinotecan (CPT-11) inhibits angiogenesis and tumor growth. J Neurooncol 99: 177-185, 2010.

23. Levin VA, Uhm JH, Jaeckle KA, Choucair A, Flynn PJ, Prados MD, Bruner JM, Chang SM, Kyritsis AP, Gleason MJ, et al; Yung WKA: Phase III randomized study of postradiotherapy chemotherapy with alpha-difluoromethylornithine-procarbazine, $\mathrm{N}$-(2-chloroethyl)-N'-cyclohexyl-N-nitrosurea, vincristine (DFMO-PCV) versus PCV for glioblastoma multiforme. Clin Cancer Res 6: 3878-3884, 2000.

24. Tsuboi K, Saijo K, Ishikawa E, Tsurushima H, Takano S, Morishita Y and Ohno T: Effects of local injection of ex vivo expanded autologous tumor-specific T lymphocytes in cases with recurrent malignant gliomas. Clin Cancer Res 9: 3294-3302, 2003.

25. Lamszus K, Ulbricht U, Matschke J, Brockmann MA, Fillbrandt $\mathrm{R}$ and Westphal M: Levels of soluble vascular endothelial growth factor (VEGF) receptor 1 in astrocytic tumors and its relation to malignancy, vascularity, and VEGF-A. Clin Cancer Res 9: 1399-1405, 2003

26. Sathornsumetee S, Cao Y, Marcello JE, Herndon JE II, McLendon RE, Desjardins A, Friedman HS, Dewhirst MW, Vredenburgh JJ and Rich JN: Tumor angiogenic and hypoxic profiles predict radiographic response and survival in malignant astrocytoma patients treated with bevacizumab and irinotecan. J Clin Oncol 26: 271-278, 2008.

27. Hasselbalch B,Eriksen JG, Broholm H, Christensen IJ, GrunnetK, Horsman MR, Poulsen HS, Stockhausen MT and Lassen U: Prospective evaluation of angiogenic, hypoxic and EGFR-related biomarkers in recurrent glioblastoma multiforme treated with cetuximab, bevacizumab and irinotecan. APMIS 118: 585-594 2010.

28. Lu-Emerson C, Snuderl M,Kirkpatrick ND, Goveia J, Davidson C, Huang Y, Riedemann L, Taylor J, Ivy P, Duda DG, et al: Increase in tumor-associated macrophages after antiangiogenic therapy is associated with poor survival among patients with recurrent glioblastoma. Neuro Oncol 15: 1079-1087, 2013.

29. Duda DG, Willett CG, Ancukiewicz M, di Tomaso E, Shah M, Czito BG, Bentley R, Poleski M, Lauwers GY, Carroll M, et al: Plasma soluble VEGFR-1 is a potential dual biomarker of response and toxicity for bevacizumab with chemoradiation in locally advanced rectal cancer. Oncologist 15: 577-583, 2010.
30. Batchelor TT, Sorensen AG, di Tomaso E, Zhang WT, Duda DG, Cohen KS, Kozak KR, Cahill DP, Chen PJ, Zhu M, et al: AZD2171, a pan-VEGF receptor tyrosine kinase inhibitor, normalizes tumor vasculature and alleviates edema in glioblastoma patients. Cancer Cell 11: 83-95, 2007.

31. Batchelor TT, Duda DG, di Tomaso E, Ancukiewicz M, Plotkin SR, Gerstner E, Eichler AF, Drappatz J, Hochberg FH, Benner T, et al: Phase II study of cediranib, an oral pan-vascular endothelial growth factor receptor tyrosine kinase inhibitor, in patients with recurrent glioblastoma. J Clin Oncol 28: 2817-2823, 2010.

32. Gerstner ER, Eichler AF, Plotkin SR, Drappatz J, Doyle CL, Xu L, Duda DG, Wen PY, Jain RK and Batchelor TT: Phase I trial with biomarker studies of vatalanib (PTK787) in patients with newly diagnosed glioblastoma treated with enzyme inducing anti-epileptic drugs and standard radiation and temozolomide. J Neurooncol 103: 325-332, 2011.

33. Quant EC, Batchelor T, Lassman AB, Schiff D, Kaley TJ, Wong E, Mikkelsen T, Drappatz J, Norden AD, Beroukhim R, et al: Preliminary results from a multicenter, phase II, randomized, noncomparative clinical trial of radiation and temozolomide with or without vandetanib in newly diagnosed glioblastoma. J Clin Oncol 29: 2069, 2011.

34. Shiose S, Sakamoto T, Yoshikawa H, Hata Y, Kawano Y, Ishibashi T, Inomata H, Takayama K and Ueno H: Gene transfer of a soluble receptor of VEGF inhibits the growth of experimental eyelid malignant melanoma. Invest Ophthalmol Vis Sci 41: 2395-2403, 2000.

35. Takayama K, Ueno H, Nakanishi Y, Sakamoto T, Inoue K, Shimizu K, Oohashi H and Hara N: Suppression of tumor angiogenesis and growth by gene transfer of a soluble form of vascular endothelial growth factor receptor into a remote organ. Cancer Res 60: 2169-2177, 2000.

36. Ye C, Feng C, Wang S, Wang KZQ, Huang N, Liu X, Lin Y and Li M: sFlt-1 gene therapy of follicular thyroid carcinoma. Endocrinology 145: 817-822, 2004.

37. Mahasreshti PJ, Kataram M, Wang MH, Stockard CR, Grizzle WE, Carey D, Siegal GP, Haisma HJ, Alvarez RD and Curiel DT: Intravenous delivery of adenovirus-mediated soluble FLT-1 results in liver toxicity. Clin Cancer Res 9: 2701-2710, 2003.

38. Goldman CK, Kendall RL, Cabrera G, Soroceanu L, Heike Y, Gillespie GY, Siegal GP, Mao X, Bett AJ, Huckle WR, et al: Paracrine expression of a native soluble vascular endothelial growth factor receptor inhibits tumor growth, metastasis, and mortality rate. Proc Natl Acad Sci USA 95: 8795-8800, 1998.

39. Ikeda T, Sun L, Tsuruoka N, Ishigaki Y, Yoshitomi Y, Yoshitake $\mathrm{Y}$ and Yonekura H: Hypoxia down-regulates sFlt-1 (sVEGFR-1) expression in human microvascular endothelial cells by a mechanism involving mRNA alternative processing. Biochem J 436: 399-407, 2011.

40. Jain RK: Antiangiogenesis strategies revisited: From starving tumors to alleviating hypoxia. Cancer Cell 26: 605-622, 2014.

41. Mashiko R, Takano S, Ishikawa E, Yamamoto T, Nakai K and Matsumura A: Hypoxia-inducible factor $1 \alpha$ expression is a prognostic biomarker in patients with astrocytic tumors associated with necrosis on MR image. J Neurooncol 102: 43-50, 2011.

42. Kung AL, Wang S, Klco JM, Kaelin WG and Livingston DM: Suppression of tumor growth through disruption of hypoxiainducible transcription. Nat Med 6: 1335-1340, 2000.

43. Hu B, Kou L, Li C, Zhu LP, Fan YR, Wu ZW, Wang JJ and $\mathrm{Xu}$ GX: Bifidobacterium longum as a delivery system of TRAIL and endostatin cooperates with chemotherapeutic drugs to inhibit hypoxic tumor growth. Cancer Gene Ther 16: 655-663, 2009.

44. Zhu H, Li Z, Mao S, Ma B, Zhou S, Deng L, Liu T, Cui D, Zhao Y, He J, et al: Antitumor effect of sFlt-1 gene therapy system mediated by Bifidobacterium Infantis on Lewis lung cancer in mice. Cancer Gene Ther 18: 884-896, 2011.

45. Biswal MR, Prentice HM, Dorey CK and Blanks JC: A hypoxiaresponsive glial cell-specific gene therapy vector for targeting retinal neovascularization. Invest Ophthalmol Vis Sci 55: 8044-8053, 2014.

46. Perche F, Biswas S, Patel NR and Torchilin VP: Hypoxiaresponsive copolymer for siRNA delivery. Methods Mol Biol 1372: 139-162, 2016. 